\title{
Influence of solids concentration on the microstructure of suspension plasma sprayed $\mathrm{Y}-\mathrm{TZP} / \mathrm{Al}_{2} \mathrm{O}_{3} / \mathrm{SiC}$ composite coatings
}

\author{
$\underline{\text { V. Carnicer }}{ }^{1 *}$, M.J. Orts ${ }^{1}$, R. Moreno ${ }^{2}$, E. Sánchez ${ }^{1}$
}

(1) Instituto de Tecnología Cerámica (ITC), Universitat Jaume I (UJI). Castellón, Spain

(2) Instituto Cerámica y Vidrio (ICV), Consejo Superior de Investigaciones Científicas

(CSIC). Madrid, Spain

Víctor Carnicer Cervera (* Corresponding author) Telephone number: $(+34) 964342424$

Email: victor.carnicer@itc.uji.es

Fax number: (+34) 964342425

María José Orts Tarí

Email: mariajose.orts@itc.uji.es

Rodrigo Moreno Botella

Email: $\underline{\text { rmoreno@icv.csic.es }}$

Enrique Sánchez Vilches

Email: enrique.sanchez@itc.uji.es 


\begin{abstract}
The present research focuses on the effect of feedstock suspension solid concentration on the microstructure of suspension plasma sprayed $\mathrm{Y}-\mathrm{TZP} / \mathrm{Al}_{2} \mathrm{O}_{3} / \mathrm{SiC}$ composite coatings. For this purpose, concentrated aqueous suspensions were prepared at 10, 20 and $30 \mathrm{vol} \%$ of particles. Suspensions were characterised in terms of colloidal stability, rheological behaviour and sedimentation trend. The optimised suspensions were plasma sprayed, and the thickness, porosity, amount of resolidified particles and $\mathrm{SiC}$ content in the coatings were evaluated by optical microscopy, scanning electron microscopy and X-ray diffraction.
\end{abstract}

The results revealed that stand-off distance and suspension solid content have a strong and similar influence on the coating microstructure due to the great impact that these two parameters exerts on the energy that particles and substrate receive during plasma operation. Thus, cauliflower-like microstructure is well-developed in most of the coatings, particularly for longer distances and lower solid contents. Porosity and amount of resolidified particles in the coatings are favoured by increasing the stand-off distance and decreasing the solids content, while thickness is strongly affected by solids content variation. On the other hand, Rietveld method from X-ray diffraction showed that large amount of the initial $\mathrm{SiC}$ was preserved in the final coatings whereas this amount remains almost constant for the three suspension feedstock tested.

Keywords: Thermal barrier coatings, Suspension plasma spraying, High solid content, multicomponent, self-healing 


\section{Introduction}

Thermal barrier coatings (TBCs) are advanced ceramic systems usually applied onto the metallic surface of gas-turbine engines to allow them to operate at higher temperatures for as much time as possible without failure. [1] TBCs represent complex multilayer systems with specific requirements such as high melting point, low thermal conductivity, no phase transformation at elevated temperature, high hardness and relatively low density. These systems are made up of a metallic part of the engine (e.g. combustion chamber, rotator blade), a metallic bond layer (bond coat), a developed thermally-grown oxide layer and a ceramic top coat. The bond coat is designed with intermediate properties between the metallic substrate and ceramic top coat to compensate the different thermal expansions, to improve the adhesion between layers and to produce an impervious thermal oxide layer (TGO) with good mechanical properties at high temperature. The TGO comprises a developed thin layer which is responsible for reducing the oxygen diffusivity towards the substrate. Finally, the ceramic top coat is made of refractory ceramic oxides because these materials exhibit excellent thermal properties as well as much higher melting points than those of metallic substrates. [2-4]

According to the state of the art, zirconia stabilized with yttria is the main oxide used in the formation of the ceramic layer of a TBC, due to its good thermal stability, high melting point $\left(2700{ }^{\circ} \mathrm{C}\right)$ and low thermal conductivity. Nevertheless, the more and more demanding requirements of the combustion process in advance engines result in the search of alternative TBCs systems based on different strategies as for example the addition of oxides $\left(\mathrm{Al}_{2} \mathrm{O}_{3}\right)$ to form a pseudoeutectic mixture with better mechanical and tribological properties or the incorporation of other elements $(\mathrm{Sr}, \mathrm{La} . .$.$) to form new crystalline structures as perovskite,$ pyrochlore, hexaaluminates which enhance the TBCs properties such as refractoriness, resistance to high temperature and corrosion by ashes attack [4]. As a result, new coatings that improve the efficiency and protection over the metals offered by the conventional TBC are currently under intense research activity. [5]

Although there is a great number of potential thermal spray techniques to obtain TBCs, physical vapor deposition (EB-PVD) and atmospheric plasma spraying (APS) represent the two most employed techniques [2]. The first method produces a characteristic columnar structure with low inter- and intra-granular porosity that increases the lifetime of TBC by reducing the stress during the thermal cycle. Nevertheless, EB-PVD displays some drawbacks as excessive cost and low deposition rate in comparison with APS. Thus, APS process is an easy, inexpensive and versatile technique to produce coatings from micrometric powders. However, these coatings exhibit a lamellar microstructure by stack of multiples splats which lead to relatively great porosity and cracks. As a result, APS coatings characterise by low thermal conductivity 
and good thermal insulation, the thermal stress and the probability of delamination is high though.[2][6][7].

Consequently, it is necessary to incorporate techniques to engineer microstructures which allow to balance the characteristics provided by the current deposition techniques. An alternative is to use the suspension plasma spraying process (SPS). [7] SPS technique derivates from APS process but in SPS process the feedstock particles are mixed and dispersed in a liquid to be fed into the plasma torch by injecting or atomizing through a nozzle. The use of a carrier liquid allows to employ submicron or even nanosized particles during the spray process resulting in new, enhanced coating microstructures [6,8]. Literature reports the benefits of SPS coating microstructures which relate to the appearance of columnar, cauliflower-like structure together with hierarchal porosities ranging from micrometer to nano sizes giving rise to further reduction of thermal conductivity as well as a longer operational lifetime [9]. On the other hand, as a suspension feedstock is used, the preparation and characterisation of the suspension is of paramount importance so as to obtain long time stable feedstock to avoid the agglomeration and sedimentation during the spray process which would impair final coating microstructure $[2,10]$. These requirements for the feeding suspension become more and more difficult as the solids content of the suspensions grows $[10,11]$ whereas the technical and economic benefits of minimising the amount of liquid in the suspension feedstock are evident [12]. For this reason, the preparation and use of high solids content suspension feedstocks turn into a challenging task in SPS application [13].

According to previous research, [13-15] different thermal barrier coatings have been developed with a matrix of zirconia and alumina $\left(\mathrm{Y}-\mathrm{TZP} / \mathrm{Al}_{2} \mathrm{O}_{3}\right)$ and a dispersed phase of silicon carbide (SiC) to improve the mechanical properties and to add a potential self-healing ability in the coating, respect to conventional TBC. In particular, some previous papers by the authors showed that optimal suspension feedstock containing SiC particles was successfully deposited by SPS resulting in coatings in which significant amount of the initial SiC particles were preserved [14]. However, solids content of the suspension feedstock was kept constant at the relatively low concentration of 10 vol. $\%$.

Following with this research line this paper addresses the effect of the solids content of the suspension feedstock in the SPS deposition of the same multicomponent mixture made up of an $\mathrm{Y}-\mathrm{TZP} / \mathrm{Al}_{2} \mathrm{O}_{3}$ matrix with $\mathrm{SiC}$ particles. Solids content starting from 10 vol.\% and amounting to $30 \mathrm{vol} \%$ will be used and the effect of feedstock solid concentration on the process and coatings characteristics will be assessed. Together with feedstock variation three different stand-off distances were tested: 30,40 and $50 \mathrm{~mm}$. Rheological characterisation and stability of the suspensions by sedimentation tests were determined. A special focus will be 
done on the effect of the suspension concentration on coating microstructure and on the preservation of the feedstock $\mathrm{SiC}$ particles throughout the coating matrix.

\section{Experimental}

\subsection{Suspensions preparation and characterisation}

The following commercial submicronic powders were used to prepare the multicomponent feedstock suspensions (referred as S/A/Z): $\alpha$-alumina (CT3000SG, Almatis, Germany), tetragonal zirconia polycrystals doped with 3 mol\% $\mathrm{Y}_{2} \mathrm{O}_{3}$ (TZ-3YS, Tosoh, Japan) and $\alpha$-silicon carbide (UF-15 Hermann C. Starck, Germany), with a mean particle size of $0.5 \mu \mathrm{m}, 0.4 \mu \mathrm{m}$ and $0.6 \mu \mathrm{m}$, respectively. More details on these materials were set out in a previous work [14].

The aqueous ceramic suspensions were prepared at 10, 20 and 30 vol.\% solid contents, which are equivalent to $34,54,66 \mathrm{wt} \%$. Moreover, the TZ-3YS and $\mathrm{Al}_{2} \mathrm{O}_{3}$ particles were mixed together in the weight ratio of 59.6/40.4 to favour the pseudoeutectic mixture, and $15 \mathrm{wt} \%$ of silicon carbide particles were added. As reported elsewhere [16,17], to maintain the stability of suspension two deflocculant were used: an ammonium salt of polyacrylic acid (PAA; Duramax TM D-3005, Rohm \& Haas, USA, with 35 wt\% active matter) for the oxide compounds and a synthetic polyelectrolyte (Produckt KV5088, Zschimmer \& Schwarz, Germany) for the nonoxide compound.

The three multicomponent suspensions were prepared and stabilised by ultrasonic probe and then cooled in ice-water during sonication to avoid overheating. Details of the preparation procedure have been reported elsewhere [13]. Colloidal stability of diluted suspensions was evaluated through zeta potential measurements as a function of $\mathrm{pH}$ using the Laser Doppler Velocimetry principle with dynamic back scattering (Zetasizer NanoZS, Malvern, UK). For this method, individual suspension with low solid content $(0.1 \mathrm{~g} / \mathrm{L})$ was added in a solution of $\mathrm{KCl}$, while maintaining stirring and then applying 1 minute of sonication to avoid agglomeration $[13,17]$.

All suspension feedstocks were rheologically characterised using a rheometer with double-cone and plate with a cone angle of $2^{\circ}$ and a double gap cylinder systems (Haake RS50; Thermo, Karlsruhe, Germany) operating at controlled temperature and controlled shear rate from 0 to $1000 \mathrm{~s}^{-1}$ in $5 \mathrm{~min}$, maintaining at $1000 \mathrm{~s}^{-1}$ and downloading from 1000 to $0 \mathrm{~s}^{-1}$ in $5 \mathrm{~min}$. Stability of the suspensions was assessed with a multiple light scattering equipment (Turbiscan LAB Stability ${ }^{\mathrm{TM}}$ Analyzer, Formulaction, France) which measures the variation of backscattered and transmitted light with time through a glass cell containing the suspension. More details about this procedure have been previously reported $[19,20]$. From these measurements, a Turbiscan Stability Index (TSI) ranging from 0 and 100 was estimated. TSI value close to 0 indicate that 
the suspension shows very good stability, while a value of 100 represents the opposite, i.e high sedimentation trend. TSI values were calculated using the computer program Easy Soft (Turbiscan LAB Stability ${ }^{\mathrm{TM}}$ Analyzer, Formulaction, France) from the equation:

$$
T S I=\sqrt{\frac{\sum_{i-1}^{n}\left(x_{i}-x_{B S}\right)^{2}}{n-1}}
$$

Where: $\mathrm{X}_{\mathrm{i}}$ is the mean backscattered light value for each time of measurement, $\mathrm{X}_{\mathrm{BS}}$ is the average of $\mathrm{X}_{\mathrm{i}}$ and $\mathrm{n}$ is the number of scans for the experiment.

\subsection{Coatings preparation}

Substrates used for this study were AISI-304 stainless steel with a disc geometry of $25 \mathrm{~mm} \mathrm{x}$ $10 \mathrm{~mm}$. Bond coats and top coats were obtained by using atmospheric plasma spraying (APS) and suspensions plasma spraying (SPS) techniques respectively. The equipment consisted of a monocathode gun (F4-MB, Sulzer Metco, Germany) with a $6 \mathrm{~mm}$ internal diameter anode operated by an industrial robot (IRB 1400, ABB, Switzerland). The commercial powder used to obtain the bond coat was AMDRY 997 (Oerlikon Metco, Wohlen, Switzerland), whose composition is based on NiCoCrAlTaY metallic material. The deposition parameters were those recommended by the manufacturer. Before deposition, the substrates were grit-blasted using a black corundum, cleaned with ethanol and preheated at $150^{\circ} \mathrm{C}$ to enhance the bond coat adhesion.

SPS layers were sprayed using three different suspensions (10, 20 and 30 vol.\% of solid content) and three different stand-off distances $(30,40$ and $50 \mathrm{~mm}$ ) in order to examine the join effect of both parameters on the resulting coatings while the other spray conditions used for deposition were the same for all the experiments as set out in previous works $[13,14]$. The suspensions were injected into plasma torch using a specific system developed by Instituto de Tecnologia Ceramica, consisting in a pressure container from which the liquid is pumped to a $150 \mu \mathrm{m}$ diameter nozzle going into the plasma torch. The substrates were fixed in a rotative sample holder with a perpendicular movement respect of the linear trajectory of the plasma spray [21].

\subsection{Coatings characterisation}

All microstructures were analysed on surface and cross-section using a field emission scanning electron microscope (Quanta 200FEG, FEI Company, USA) to assess splats morphology, thickness, porosity and unmelted zones. Previously to observe the cross-section, all sprayed S/A/Z coatings were cut with a diamond cutting blade at very slow speed, in order to avoid coating damage. The cut pieces were cleaned and dried at a controlled temperature of $50{ }^{\circ} \mathrm{C}$, and then mounted with an epoxy resin (EPOFIX, STRUERS). The surfaces of mounted samples were polished up to $1 \mu \mathrm{m}$. Average values of thickness, porosity and amount of unmelted zones 
in the coatings were obtained by image analysis (Micro Image software, Olympus Optical Co $\mathrm{GmBH}$, Germany, Europe) from twenty SEM images following a procedure set out elsewhere [13].

Phase composition of different coatings was determined by X-ray diffraction (XRD) with an Advance Diffractometer, Bruker D8, Theta-Theta, Germany. The analysis was carried out with both feedstock and as-sprayed powder using $\mathrm{Cu} K \alpha$ radiation $(\lambda=1.54183 \AA)$, energy settings of $40 \mathrm{kV}$ and $40 \mathrm{~mA}$ for $2 \Theta$ range between $5^{\circ}$ to $90^{\circ}$ with a scanning speed and step size of 10 $\mathrm{s}$ and $0.02^{\circ}(2 \Theta)$ respectively. Rietveld refinement analysis was carried out with DIFFRACplus TOPAS software supplied by BRUKER [22,23]. Fluorite was used as an internal standard in a $5 \%(\mathrm{w} / \mathrm{w})$ to quantify the amorphous phase. Rietveld method defines the different peaks by means of a least squares procedure until the difference between the standard sample and experimental sample is minimized. By means of the Rietveld method, it is possible to obtain the solids percentages of the different crystalline components in the coatings, since the mass absorption coefficient of all samples is constant, and the crystalline peaks intensity is proportional to the mass concentration.

\section{Results and discussion}

\subsection{Suspension feedstock preparation and characterisation}

In order to produce highly concentrated, stable suspensions, colloidal characterisation of diluted alumina and zirconia suspensions was separately carried out by means of zeta potential measurements at different dispersant concentration (PAA for both alumina and zirconia) at their corresponding natural $\mathrm{pH}$ (i.e. $\mathrm{pH} 5.85$ for $\mathrm{Al}_{2} \mathrm{O}_{3}, 5.75$ for TZ-3YS). This colloidal characterisation aims at establishing the optimal amount of dispersant for each oxide component. In Fig. 1, a similar behaviour for both oxides with regard to the deflocculant content dependence can be observed. First, the oxides are positively charged on the surface and when the PAA dispersant is added a strong change of zeta potential occurs, decreasing to negative values (from +15.5 to -24.8 for $\mathrm{Al}_{2} \mathrm{O}_{3}$ and from $+20.2 \mathrm{mV}$ to $-36.8 \mathrm{mV}$ for TZ-3YS) with the only addition of $0.1 \%$. Due to the zeta potential change produced by the dispersant addition, it can be affirmed that PAA dispersant exerts a strong influence on the surface charge of the particles, mainly at low percentages. For contents higher than $0.2 \%$ of PAA, the zeta potential value for both oxides remains stable around $-57.8 \mathrm{mV}$ and $-61.5 \mathrm{mV}$ for $\mathrm{Al}_{2} \mathrm{O}_{3}$ and $\mathrm{TZ}-3 \mathrm{YS}$ respectively, indicating that all the particles have been efficiently coated by the dispersant. Therefore, $0.2 \%$ of PAA is a good addition choice because the charge of the particles is negative and sufficiently high to favour the stabilization of the suspension. For the stabilization of SiC, Candelario et al [18] determined that the addition of PKV dispersant results in good stabilization 
for a wide range of deffloculant content, although the maximum stability is reached for $1.5 \%$ of PKV.

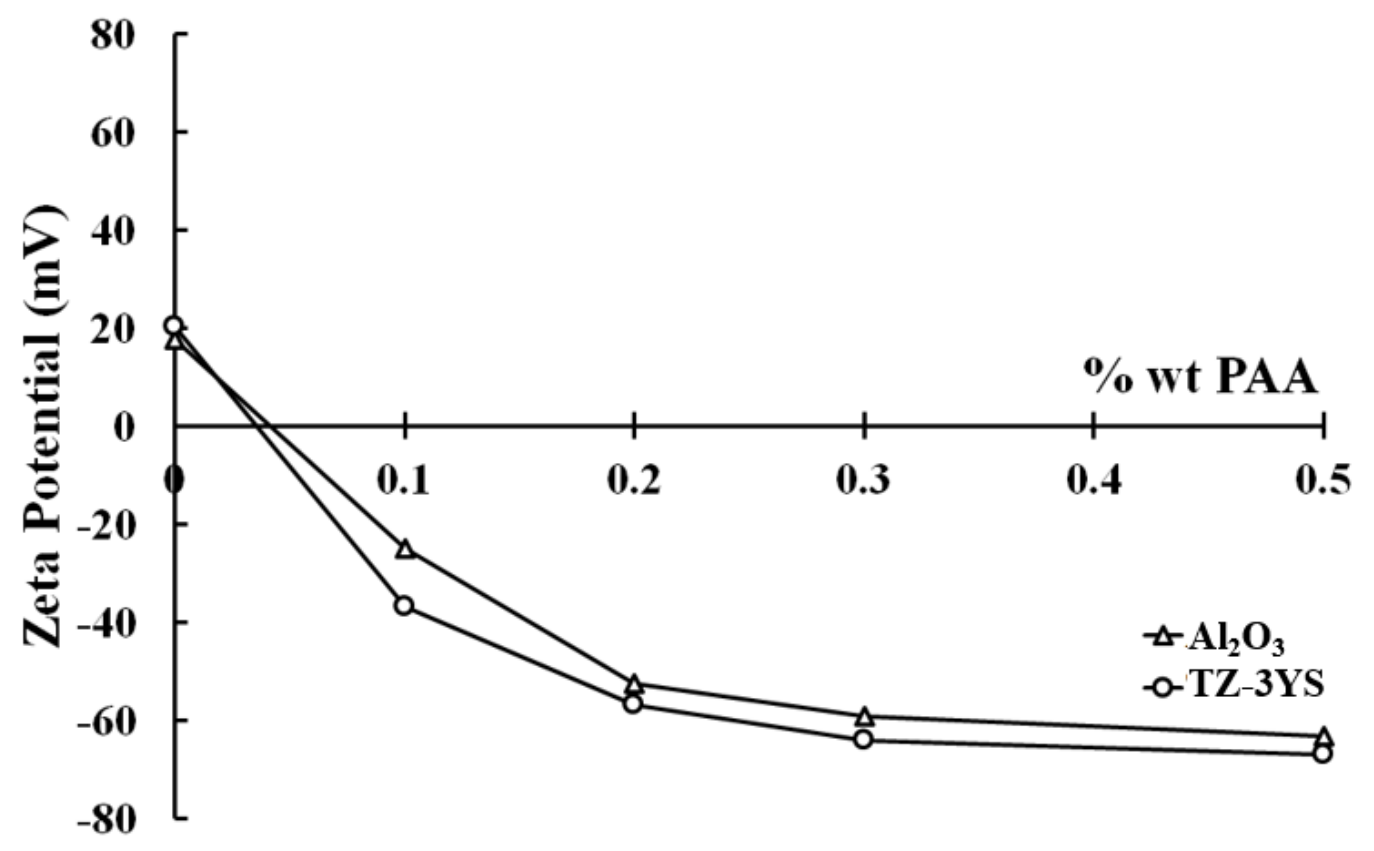

Fig. 1 Evolution of zeta potential versus concentration of deflocculant for $\mathrm{Al}_{2} \mathrm{O}_{3}$ and $\mathrm{TZ}-3 \mathrm{YS}$ diluted suspensions.

Concentrated multicomponent suspensions at 10 vol. \% 20 vol.\% and 30 vol.\% S/A/Z were prepared in distilled water with the amount of optimal dispersant as deduced above at different sonication times to assess the rheological behaviour. The values of density measurement for the suspension were 1.40, 1.71 and $2.05 \mathrm{~g} / \mathrm{cm}^{3}$ for 10,20 and 30 vol.\% respectively. The flow curves (shear stress vs shear rate) of the three suspensions are displayed in Fig. 2 ( $a, b$ and c). For better observation, magnified plot sections are represented at the top right corners inside the general plots. As it can be seen, the three suspensions present a quasi-linear (Newtonian) flow with a slight tendency toward dilatant behaviour at high shear rate. This tendency appears because suspensions have very low viscosity therefore it is possible that a slippage effect occurs between the liquid and the measurement element, as reported in the literature in some sol-gel diluted solutions [24]. However, for the highest concentration suspension (30 vol.\%), when no sonication is applied the suspension behaviour departs from linearity at lower shear rates, what is quite common as a consequence of the increase of particle interaction provoking agglomeration. When sonication is applied, the linear behaviour similar to that of lower concentration suspensions is recovered. This rheological behaviour of concentrated suspensions has already been observed in similar suspension feedstocks reported elsewhere $[25,26]$. On the other hand, viscosity can be qualitative deduced from the slope of the different (quasi) straight 
lines. As expected, viscosity grows (slope of the straight lines augments) as the solids content rises while this increase does not follow a linear trend when the load of solids is proportionally incremented. Thus, some calculated viscosity values determined at the high shear rate of 1000 $\mathrm{s}^{-1}$ in $1 \mathrm{~min}$. sonicated suspensions were as follows: $3.4,4.8$ and $8.4 \mathrm{mPa} \cdot \mathrm{s}$ for 10,20 and 30 vol.\% suspensions, respectively. Another information obtained from flow curves is thixotropy (suspension thickening with time) which can be estimated from the area enclosed by the upper and lower curves of the shear stress vs shear rate diagram [25,27]. The calculated thixotropy values for sonicated suspensions were very small. Hence, for 1 min. sonication calculated suspension thixotropy values were the following: lower than $30 \mathrm{~Pa}$ for 10 and 20 vol.\% suspensions and $330 \mathrm{~Pa}$ for $30 \mathrm{vol} . \%$ suspension. Finally, the optimal time of sonication is fixed in one minute for all suspensions because the minimum viscosity is achieved, although the optimal time for the suspension of 10 vol.\% was higher ( 3 minutes). Nevertheless, as the difference in viscosity values between 3 and 1 minute of sonication was very small $(0.2 \mathrm{mPa} \cdot \mathrm{s})$, the best time was also fixed in 1 minute to avoid heating and particle agglomeration. 

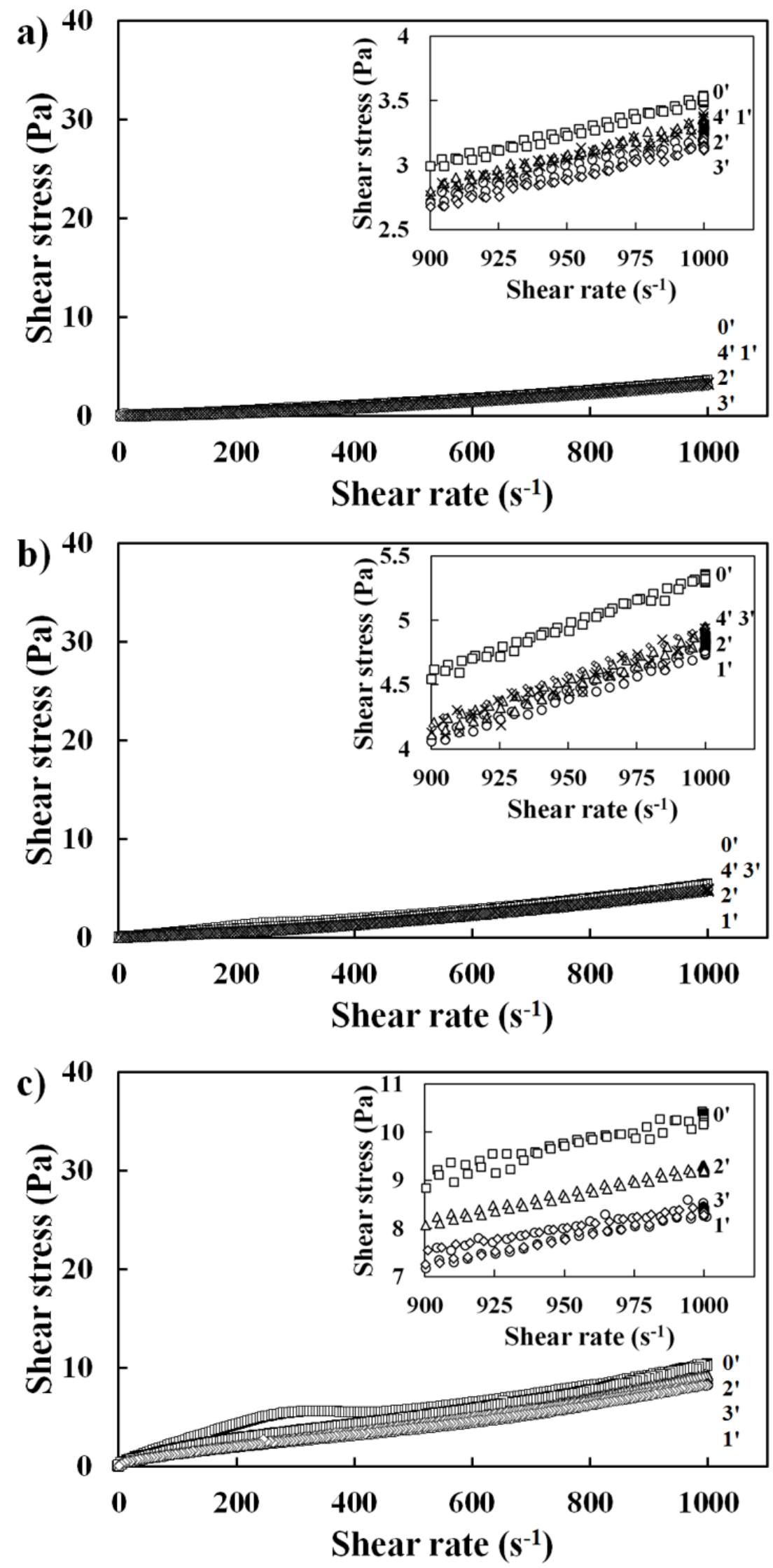

Fig. 2 Rheological behaviour of S/A/Z multicomponent suspensions at a) 10 vol. \% b) 20 vol.\% and c) 30 vol. \% . The number at right of each curve denotes the sonication time in minutes. Within each figure, a zoom of the curves can be seen for easy viewing. 
SPS technique shows some limitations with regard to suspension feedstock viscosity since an excess of viscosity makes the suspension pumping and spraying more difficult and eventually can result in clogging of the spraying injector [2,28]. For this reason, in Fig. 3 the effect of solids concentration of the suspension feedstock on suspension viscosity has been plotted. Suspensions of solids contents up to 50 vol.\% were prepared and the viscosity curves were obtained as set out above. The viscosity values were estimated at a high shear rate value of 1000 $\mathrm{s}^{-1}$ to avoid agglomeration effect. As observed, for solids contents higher than $30 \mathrm{vol} \%$ the viscosity rapidly increases following an exponential law as consequence of the enhancement of particle interaction and agglomeration [24,27]. Assuming a maximum viscosity value of 20 $\mathrm{mPa} \cdot \mathrm{s}$ for the SPS process to proceed without suspension feeding problems [16] $30 \mathrm{vol} \%$ could be considered an upper limit for the feedstock addressed in this work.

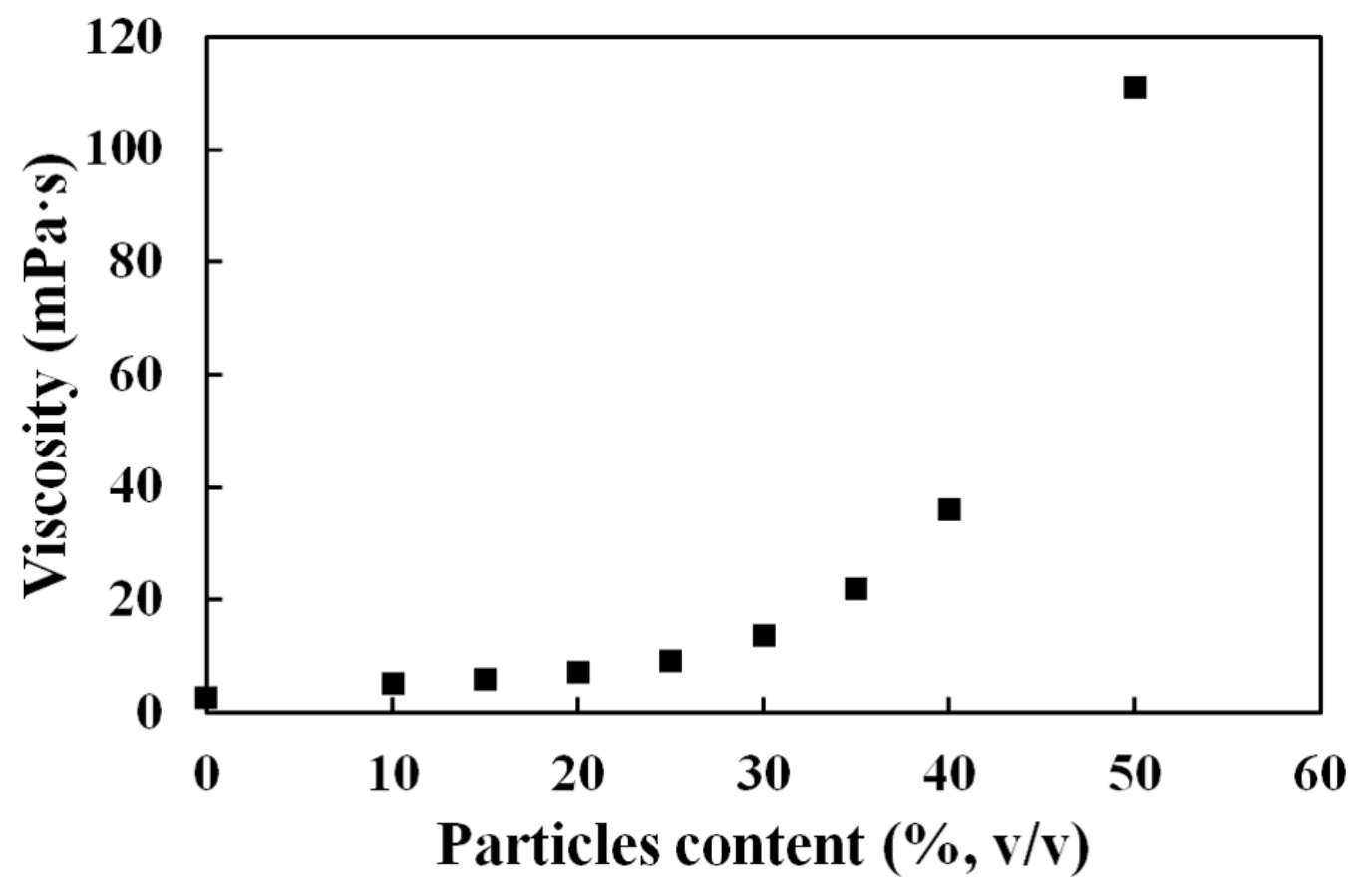

Fig. 3 Viscosity of S/A/Z suspensions at $1000 \mathrm{~s}^{-1}$ for different solids content.

In Fig. 4, we can observe the sedimentation trend of all the suspensions by the TSI coefficient. On the one hand, the three suspensions increase their respective coefficient value with time indicating that sedimentation trend rises. As expected, as the solids concentration grows, TSI values decrease at any time as a consequence of much more particle interaction and agglomeration in higher concentrated suspensions resulting in viscosity increase. However, the effect is hardly observed when the concentration goes from 10 vol. $\%$ to 20 vol. $\%$ while it is quite significant from $20 \mathrm{vol} . \%$ to $30 \mathrm{vol} . \%$. This finding agrees with the previous observation 
on the non-linear effect of solids concentration on rheological behaviour of suspensions as set out in Fig. 3. For the SPS process, it is of special interest to analyse the stability range for the suspension to be used without sedimentation or stability problems. If we consider an index value of 5 as a guarantee of stability (very low sedimentation tendency), it can be seen that the suspension at $30 \mathrm{vol} . \%$ could remain stable for longer than 12 hours while the other two could be used till 6 hours. In addition, in all cases the suspensions were easily redispersible by simple agitation, recovering their initial characteristics and homogeneity. In relation to the latter, it is worth remembering that the suspensions are subjected to continuous agitation during storage in the containers of the SPS installation. All these results allow us to conclude that suspensions could be used in the SPS process without sedimentation problems.

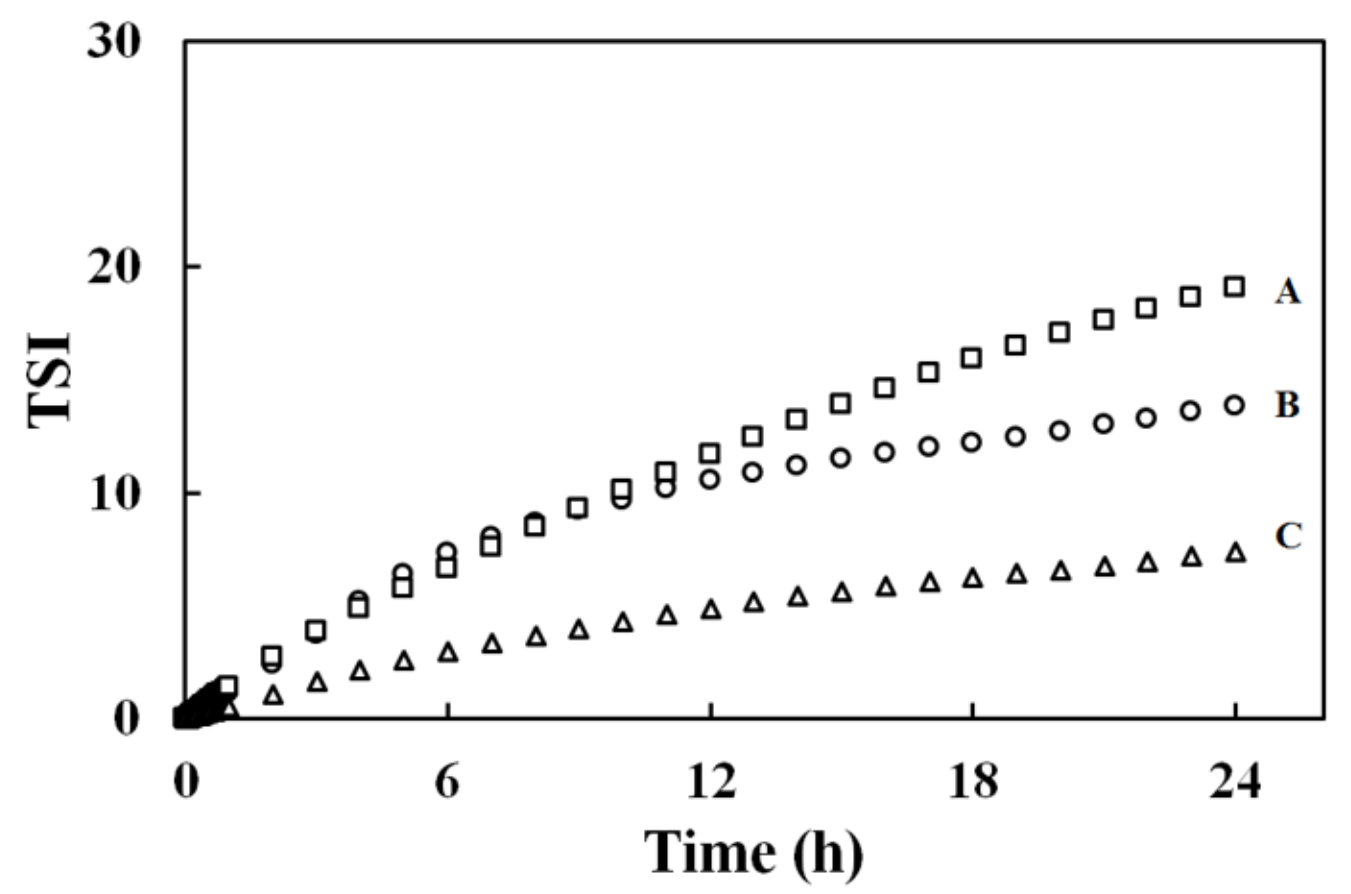

Fig. 4 Comparison of turbiscan stability index (TSI) in function of time for different suspension. A: 10 vol.\%, B: 20 vol.\% and C: 30 vol.\%.

\subsection{Coating microstructure}

In Fig. 5, disc samples of the coatings obtained at different stand-off distances from the three solid content suspension feedstock can be observed. Looking at a given solid concentration in the suspension feedstock, decreasing stand-off distance results in an increase of surface temperature of the substrate observable by the surface darkening. Respect to the solid content, a similar effect was observed when the suspension solid concentration was augmented as a consequence of the corresponding decrease of water content in the suspension requiring less energy for the water evaporation to occur. Therefore, with the modification of both variables (stand-off distance and suspension solid concentration) it is possible to modify the temperature received by the particles and the substrate. Nevertheless, specific combinations of these two 
parameters can contribute with an excess of energy as observed for the sample obtained with the shortest stand-off distance $(30 \mathrm{~mm})$ and the highest suspension solid concentration (30 vol.\%). Under these conditions an incipient delamination of coatings took place by thermal shock as observed in Fig. 5. As a consequence, stand-off distance should carefully be adjusted for a specific solid concentration in the suspension feedstock.

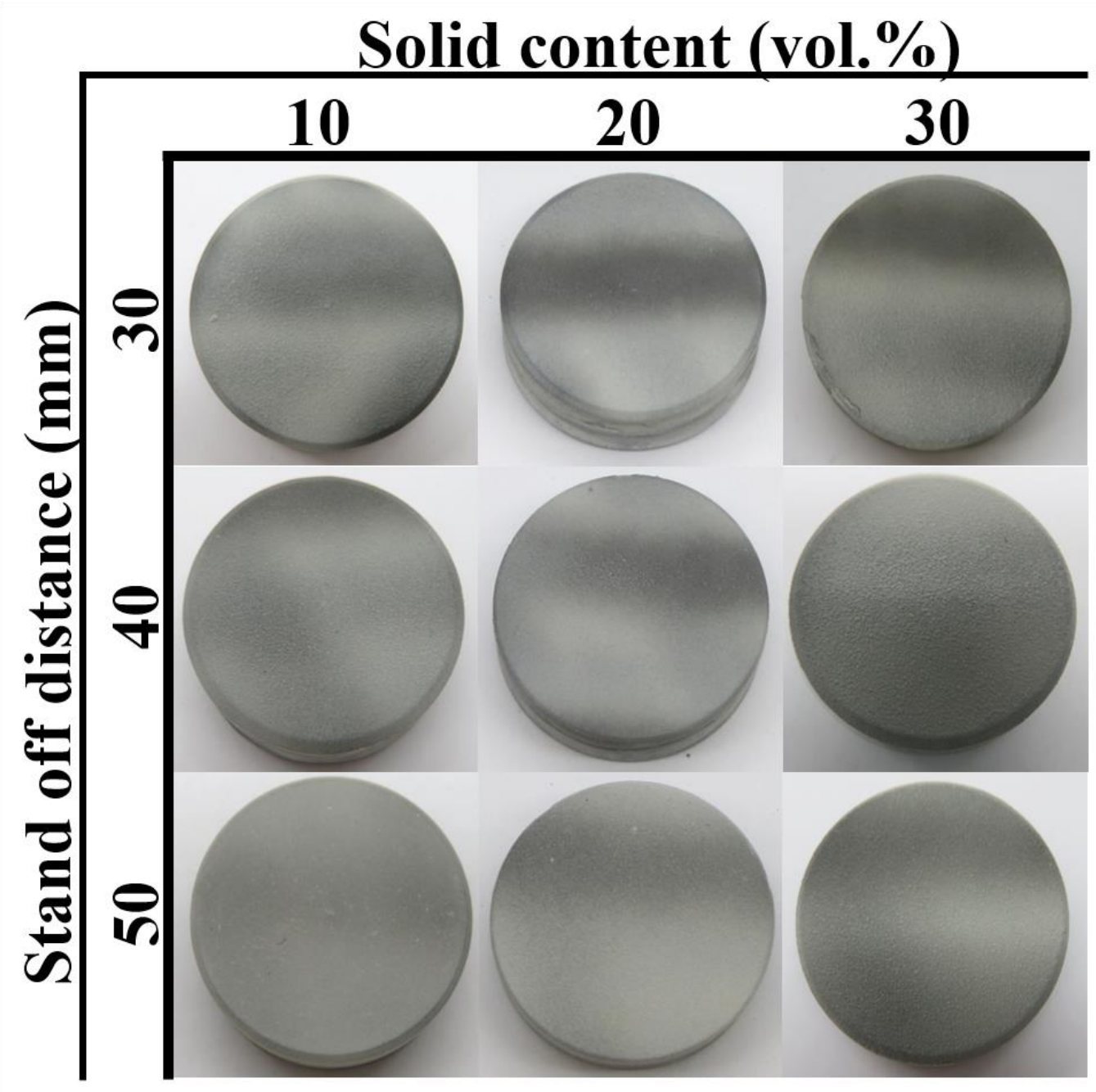

Fig. 5 Macroscopic view of the coatings obtained from the nine deposition experiments. 


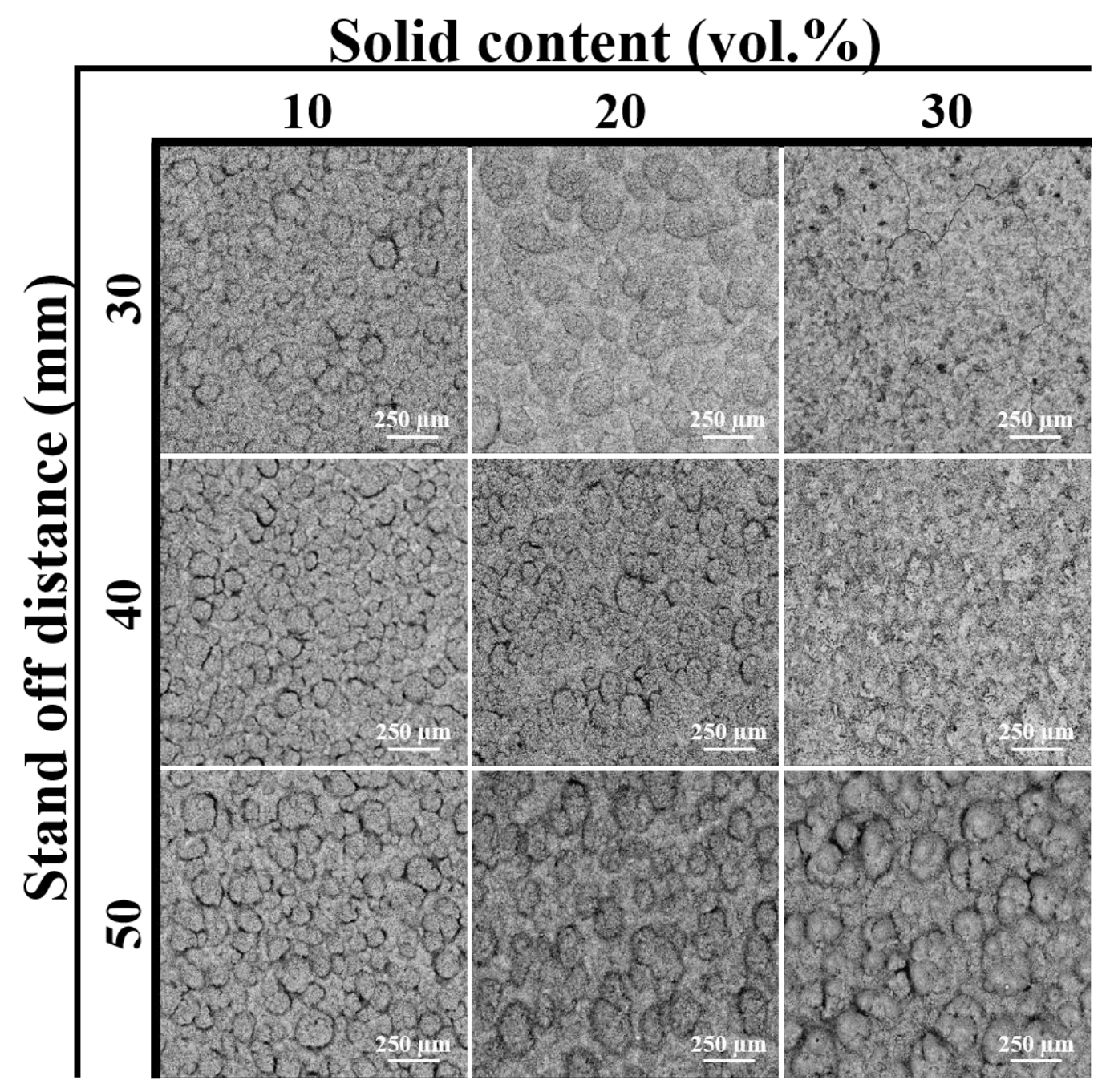

Fig. 6 SEM top surface micrograph obtained with the combination of stand-off distance and solid content in the suspension feedstock (nine experiments)

In Fig. 6, the surface micrographs by SEM of the nine coating combinations can be observed. This surface view allows to show the cauliflower-like structure typically built-up during SPS process [28]. As reported in the literature, this cauliflower structure relates to the columnar structure observable through the cross-sectional area of thick SPS coatings [29,30]. As observed, the stand-off distance exerts an important influence on the formation and growth of cauliflower-like structure because at shorter distance particles impact almost completely melted on the substrate. This fact produces a strong compaction of the splats on the coating and the practically disappearance of the cauliflowers. For longer stand-off distance particles temperature decreases as a consequence of the longer travelling distance leading to the appearance of resolidification phenomenon together with the drag forces contribution giving rise to the development and growth of the cauliflowers. For this reason, the longest stand-off distance of $50 \mathrm{~mm}$ displays the largest columnar structures. The effect of stand-off distance is similar to that observed when plasma energy in the SPS process is modified [28]. 
Literature extensively reports the effect of diverse parameters such as substrate roughness, torch linear speed, torch energy or suspension feed rate on the formation of the columnar structure $[28,29,31]$, however, the influence of solid content of suspension feedstock has been hardly treated [16]. When observing Fig. 8 the cauliflower-like structure is clearly visible for solids contents lower than 20 vol.\%. This is because these suspensions which have lower viscosity give rise after injection to a large amount of droplets with fewer particles inside [30]. Therefore, during water evaporation particles receive less energy to melt remaining isolated in the centre and periphery of the torch. The particles in the centre of the plasma torch melt and then easily adhere to the surface, while the partially or unmelted particles in the periphery lead to new imperfections for the growth of column structures [28,32].

The coatings sprayed using 30 vol. \% of particles and shorter stand-off distances hardly generated cauliflowers. In these cases, only some small cauliflowers were observed with very rounded and melted edges because less droplets containing higher concentration of particles are fed into the torch, decreasing the energy lost by water evaporation. In the distance of $50 \mathrm{~mm}$ for $30 \mathrm{vol} . \%$, the columnar structure is again visible, observing large cauliflowers with a round and melted aspect. This finding suggests that the longest stand-off distance compensates the effect of cauliflower elimination associated to the highest solids content suspension. 


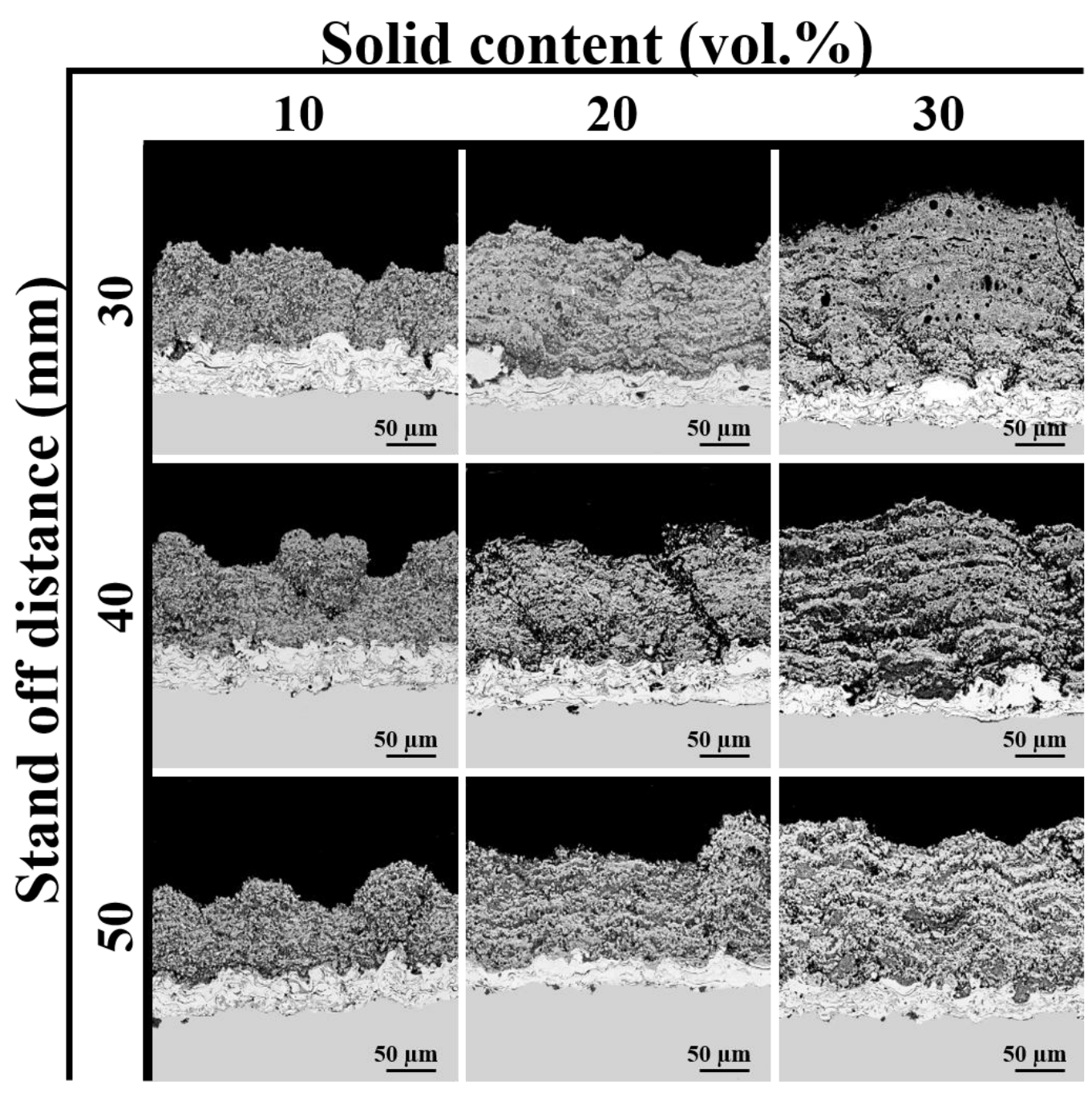

Fig. 7 SEM cross-section micrographs of the coatings obtained with interaction of stand off distance and solid content.

Cross section micrographs of the coatings are displayed in Fig. 7. In the sprayed coatings section, the columnar structure is not well developed for any coating because it is probable that the plasma energy as well as the coating thickness may not be sufficient, although it seems to begin to form in the surface layers. In Fig. 7 all coatings were produced under the same conditions with the exception of stand-off distance and suspension solid content. For this reason, the strong effect of suspension solid content on the coating thickness was clearly observed, due to the high amount of particles in the suspensions that favour much higher deposition of material per pass. On the contrary, stand-off distance hardly influences on coating thickness. Moreover, inter-pass boundary layers can be seen within the structure of the individual segments for solid contents above $20 \mathrm{vol} . \%$. The formation of these layers can be attributed to particles deposition in the semi-molten or re-solidified state leading to layers of higher porosity and resolidification origin. 
In Fig. 8, the thickness, porosity and resolidified zones in the coatings determined by image analysis are shown in 3D diagrams. The definition as well as the procedure for their determination have been reported in other works [14,33]. As previously discussed, coating thickness (Fig. 8a) was not affected by the spray distance (i.e., 75, $7270 \mu \mathrm{m}$ for 30, 40, $50 \mathrm{~mm}$ respectively and 10 vol.\%), however, the solid content dramatically impacts on coating thickness (i.e., 75, 110, $150 \mu \mathrm{m}$ for 10, 20, $30 \mathrm{vol} \%$ respectively and $30 \mathrm{~mm}$ of distance).

Fig. $8 \mathrm{~b}$ shows that coating porosity increases as the solid content grow. In this way, the porosity is $5.5 \%$ at the lowest solid concentration and $6.5 \%$ at the maximum solid concentration for 30 $\mathrm{mm}$ distance, and the same effect is observed in other distances and solids contents (i.e., 5.6\% to $14.4 \%$ for $40 \mathrm{~mm}$ and $8.2 \%$ to $15.1 \%$ for $50 \mathrm{~mm}$ ). In addition, as expected longer stand-off distance produced greater porosities. The effect observed in porosity with solids content contrasts with previous literature reports. This is probably attributed to the solids content in the suspension feedstock used in this research (from 10 vol. $\%$ to 30 vol. $\%$, i.e from $\sim 34 \mathrm{wt} \%$ to $\sim 66 \mathrm{wt} \%$ ), which are much higher than those commonly employed in SPS processes (1-5 vol.\%) $[9,28,31]$. This high concentration can produce an excess of particles in the plasma torch and therefore, less number of molten particles. This reduced amount of molten particles favours that their impact on the substrate generates greater irregularities in coatings (porosities and resolidified particles). This assumption can be confirmed by observing the Fig. $8 \mathrm{c}$, where the effect produced by stand-off distance and solids concentration on the amount of resolidified particles can be appreciated that coincides with that observed on porosity. This is because at greater stand-off distance the particles show higher probability of leaving plasma torch periphery, therefore the cooling time for travelling particles grows. Figs. $8 \mathrm{~b}$ and $8 \mathrm{c}$ reveal a clear parallelism between the effect of stand-off distance and suspension solid concentration on coating microstructure, confirming the observations discussed from the surface micrographs as well as the mechanism occurring during the formation of SPS layers.

Fig.7 showed that increasing of suspension solid concentration gave rise to an expected augmentation of coating thickness. However, it should be analysed if the deposition efficiency is also affected. Thus, Table 1 shows the deposition thickness and deposition efficiency (the ratio between the amount of solid fed into the plasma torch and solid deposited on the substrate). As it can be observed, the increase of particles in the suspension caused the decrease of the deposition efficiency. As a result of the greater amount of solids in the suspensions, less plasma torch energy was available for the heat treatment of individual particles resulting in lower deposition efficiencies. Nevertheless, the much higher amount of solid when the suspension 
concentration increases counterbalances the above effect giving rise to larger deposition rate and consequently, coating thickness as observed in Table 1.

Table 1 Values of deposition efficiency and rate for all experiments.

\begin{tabular}{ccccc}
\hline $\begin{array}{c}\text { Solids loading } \\
(\mathbf{c . v o l} \%)\end{array}$ & $\begin{array}{c}\text { Distance } \\
(\mathbf{m m})\end{array}$ & $\begin{array}{c}\text { Deposition } \\
\text { efficiency }(\boldsymbol{\%})\end{array}$ & $\begin{array}{c}\text { Deposition } \\
\text { rate } \\
(\boldsymbol{\mu m} / \mathbf{p a s s})\end{array}$ & $\begin{array}{c}\text { Coatings } \\
\text { thickness } \\
(\boldsymbol{\mu m})\end{array}$ \\
\hline \multirow{2}{*}{10} & 30 & 59 & 15 & 75 \\
& 40 & 56 & 14 & 72 \\
& 50 & 52 & 14 & 70 \\
\hline \multirow{2}{*}{20} & 30 & 43 & 22 & 110 \\
& 40 & 38 & 21 & 108 \\
& 50 & 32 & 20 & 100 \\
\hline 30 & 30 & 36 & 30 & 150 \\
& 40 & 35 & 29 & 146 \\
& 50 & 32 & 28 & 142 \\
\hline
\end{tabular}


a)

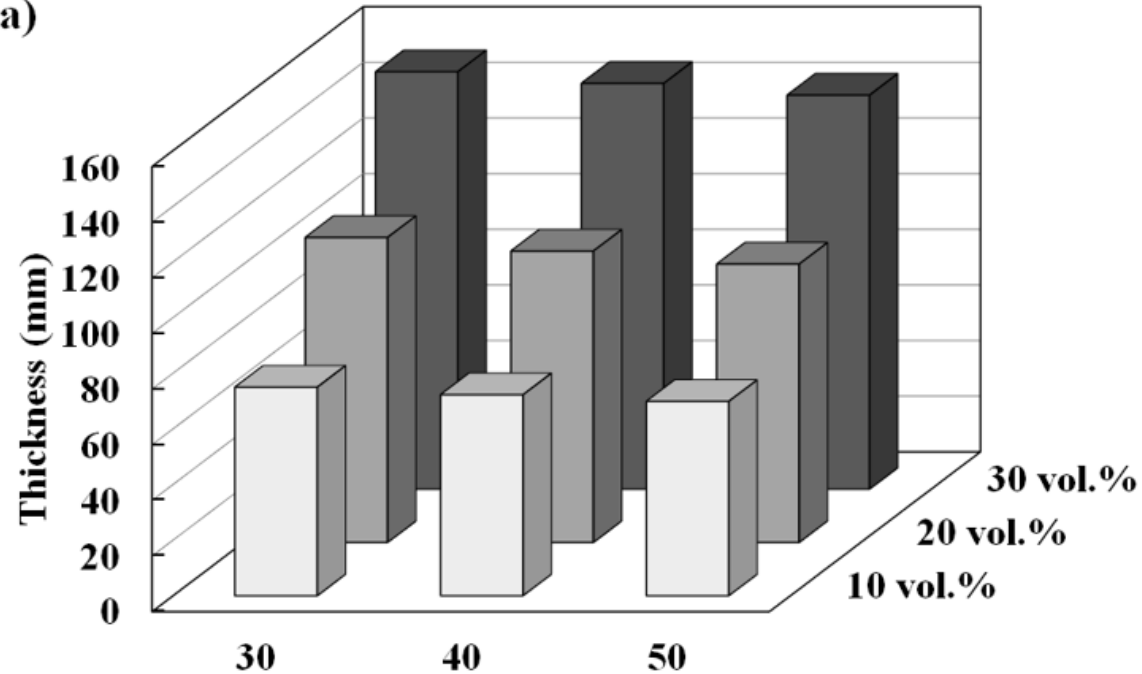

Stand off distance ( $\mathrm{mm})$

b)

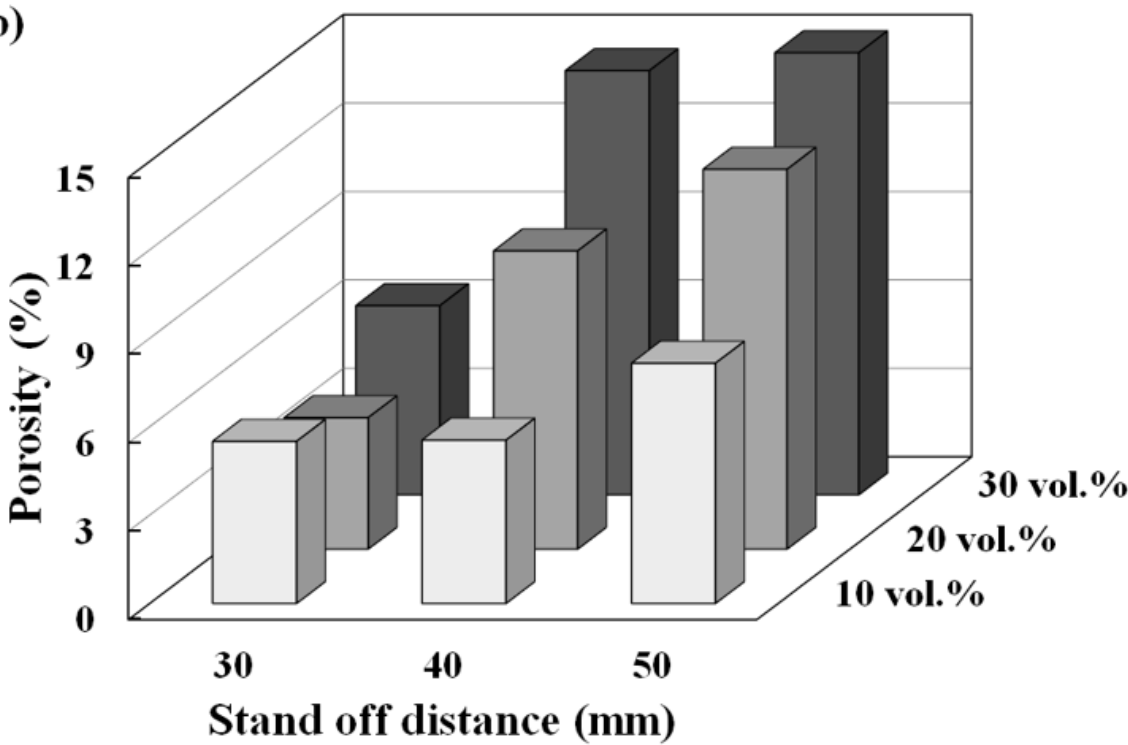

c)

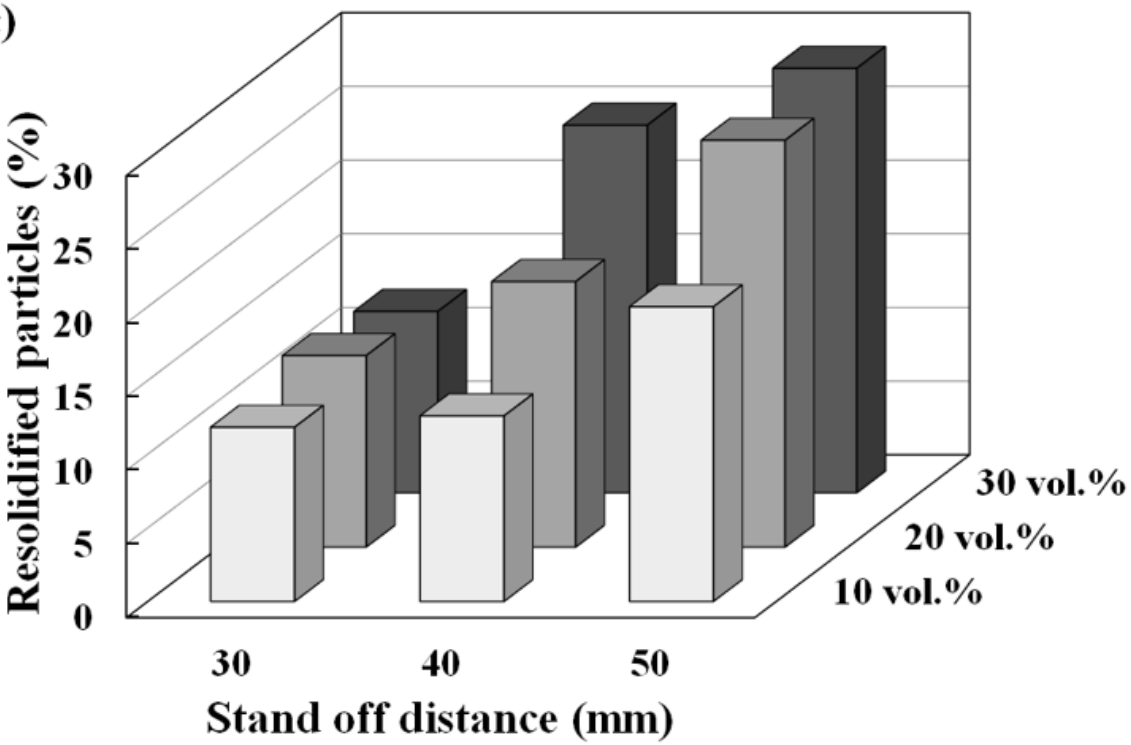

Fig. 8 Variation of thickness, porosity and amount of resolidified particles in the studied coatings with suspension solid content and stand-off distance. 


\subsection{Preservation of $\mathrm{SiC}$ in the coatings}

Fig. 9 shows the XRD patterns of the as-sprayed coatings obtained from the 10, 20 and 30 vol.\% solid content suspension at the same stand-off distance of $40 \mathrm{~mm}$ as well as the pattern of the feeding powder for comparison purposes. Similar patterns were obtained for the other two stand-off distances. The figure reveals that all coatings were practically identical, in terms of crystalline phase content. As expected, tetragonal stabilised zirconia and corundum which comprise the coating matrix represent the major phases in all samples. Some monoclinic zirconia (baddeleyite) is also observed in the starting powder but it practically disappears in the coatings due to the high temperatures of torch. As previously reported, the content of monoclinic zirconia in the feedstock powder comes from the commercial zirconia powder [30].

The silicon carbide peak was difficult to observe in XRD patterns because of it appears overlapped with alumina and zirconia peaks [14]. For this reason, Fig. 10 shows a higher magnification of all XRD patterns scanned at diffractions angles from $33^{\circ}$ to $37^{\circ}$ since over this zone the highest intensity peak of silicon carbide, specifically at $35.65^{\circ}$, is localised. The quantification of $\mathrm{SiC}$ crystalline phase preserved (referred as residual) in the coatings regarding the amount contained in the feedstock powder (15 wt $\%)$ was carried out as set out above by Rietveld method. The findings can be observed in Table 2. As it can be appreciated, around 60 wt $\%$, more specifically between 55-67 wt\% of the initial silicon carbide is preserved (not decomposed) in the coatings. Besides, the solids content in the suspension feedstock does not appear to affect on the preserved amount of SiC. Similar findings were obtained by the authors in a previous paper [14]. Nevertheless, the amount of the preserved $\mathrm{SiC}$ in the coating reported in this research is somewhat lower than that reported in the previous work as a consequence of the use of a much more accurate determination procedure (Rietveld method) in which the whole DRX pattern instead of isolated peaks are taken into account for the phase assessment. On the other hand, no indications of silicon carbide presumably oxidised during plasma deposition are detected in the XRD pattern. These results confirm that the SPS process, in combination with a pseudoeutectic oxide matrix (TZ-3YS and $\mathrm{Al}_{2} \mathrm{O}_{3}$ ) can be an useful tool to produce TBCs with $\mathrm{SiC}$ disperse phase since large amounts of the initial $\mathrm{SiC}$ particles are preserved in the final coatings. Ongoing research aims at increasing the proportion of silicon carbide preserved by adding some new compounds in the suspension feedstock. 


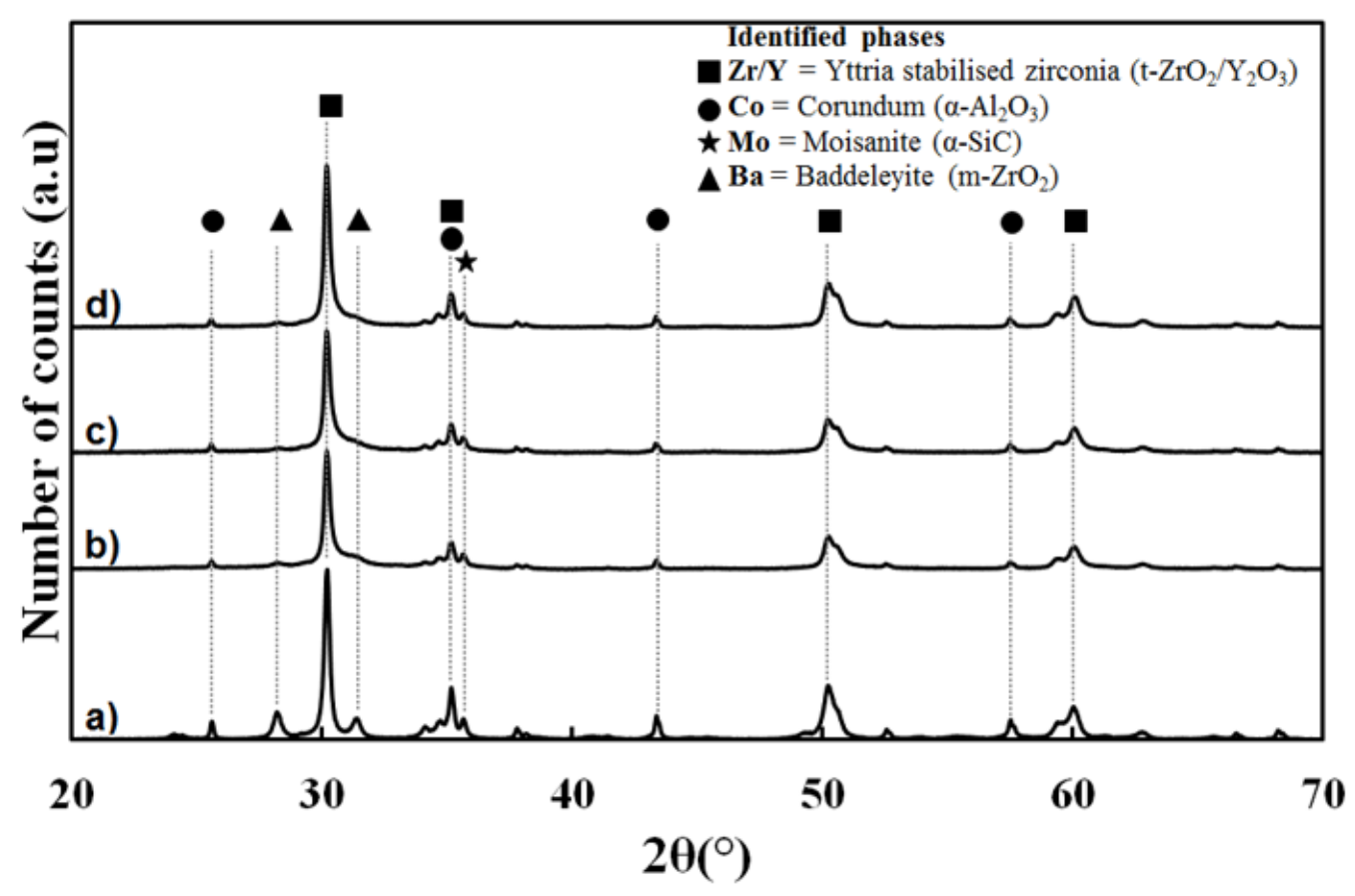

Fig. 9 XRD patterns of the feedstock powder as well as of the powders of coatings obtained from all conditions at the distance of $40 \mathrm{~mm}$ with $15 \mathrm{wt} \%$ of SiC. a) feedstock powder, b) 10 vol.\%, c) 20 vol.\% and d) 30 vol.\%.

Table 2 Results of quantitative XRD Rietveld analysis

\begin{tabular}{ccccc}
\hline Condition & Type & $\begin{array}{c}\text { Crystalline phase } \\
\text { Moisanite }(\alpha-\mathrm{SiC})\end{array}$ & $\begin{array}{c}\text { Residual* } \\
(\text { Phase, wt \%) }\end{array}$ \\
\hline Feedstock powder & A & Before plasma & $15 \pm 1$ & -- \\
10 vol.\% & B & After plasma & $09 \pm 1$ & 58 \\
20 vol.\% & C & After plasma & $10 \pm 1$ & 67 \\
30 vol.\% & D & After plasma & $08 \pm 1$ & 55 \\
\hline
\end{tabular}

*(area in plasma sprayed powder/peak area in feedstock)*100

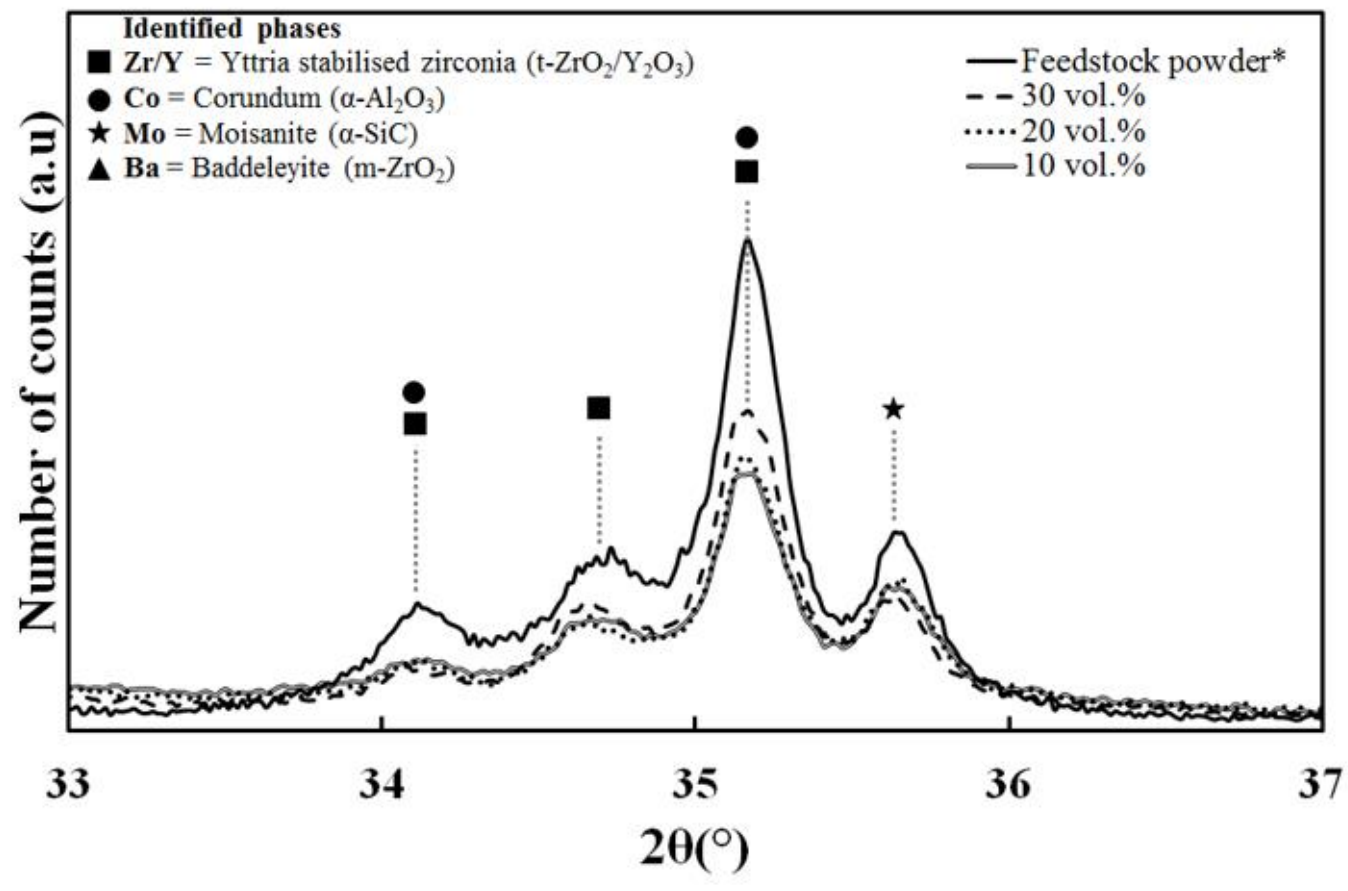

Fig. 10 Magnification of XRD patterns of samples in Figure 9 


\section{Conclusions}

In this study, a better understanding of the dependences between the coating microstructure and some spraying conditions (stand-off distance and feedstock solids content) was targeted. For this purpose, three aqueous suspensions of $\mathrm{TZ}-3 \mathrm{YS} / \mathrm{Al}_{2} \mathrm{O}_{3} / \mathrm{SiC}$ with different solid content were prepared as feedstocks for SPS deposition. The multicomponent suspensions were characterised in terms of colloidal stability and rheological behaviour. In this way, prepared suspensions displayed viscosities lower than $10 \mathrm{mPa} \cdot \mathrm{s}$ with almost null thixotropy with 1 minute of sonication.

Optimised suspensions feedstock were sprayed at the same spraying conditions onto AISI304 substrates in order to compare the effect produced by stand-off distance and feedstock solid content on coating microstructure. It was observed that the cauliflower-like structure intensifies when the distance increases and the solid content decreases. The results showed that stand-off distance and suspension solid content exerted a strong and similar influence on the coating microstructure due to the great impact of these variables on the energy supplied to particles and substrate during plasma operation. Microstructural features observation revealed a significant influence of solid content in the coatings thickness (doubling the thickness from 75 to $150 \mu \mathrm{m}$ when solids content grew from 10 to $30 \mathrm{vol} . \%)$. Moreover, values of porosity and regions of resolidified particles increased when longer distances and higher suspension concentration were used. Finally, Rietveld method from X-Ray diffraction showed that a large content of the starting silicon carbide (around $60 \%$ ) is preserved in the final coatings, whereas no effect of suspension concentration on the amount of preserved phase was observed. 


\section{Acknowledgements}

The authors of this work are grateful to support of Spanish Ministry of Economy, Industry and Competitiveness and FEDER Funds under the Grant no MAT2015-67586-C3-R, and the Research Promotion Plan of the Universitat Jaume I for the predoctoral fellowship (re. PREDOC/2017/51).

\section{References}

[1] D.R. Clarke, M. Oechsner, N.P. Padture, Thermal-barrier coatings for more efficient gasturbine engines, MRS Bull. 37 (2012) 891-898. doi:10.1557/mrs.2012.232.

[2] A. Guignard, Development of thermal spray processes with liquid feedstocks, Schriften des Forschungszentrums Jülich Reihe Energie \& Umwelt / Energy \& Environment, Jülich, Germany, 2012. http://www.fz-juelich.de/zb/juwel.

[3] R. Gadow, M. Floristán, Future Development of Thermal Spray Coatings: Types, Designs, Manufacture and Applications, Woodhead publishing, 2015. doi:10.1016/B978-0-85709-769-9.00011-7.

[4] X.Q. Cao, R. Vassen, D. Stoever, Ceramic materials for thermal barrier coatings, J. Eur. Ceram. Soc. 24 (2004) 1-10. doi:10.1016/S0955-2219(03)00129-8.

[5] E. Bakan, R. Vaßen, Ceramic top coats of plasma-sprayed thermal barrier coatings: materials, processes, and properties, J. Therm. Spray Technol. 26 (2017) 992-1010. doi:10.1007/s11666-017-0597-7.

[6] W. Fan, Y. Bai, Review of suspension and solution precursor plasma sprayed thermal barrier coatings, Ceram. Int. 42 (2016) 14299-14312. doi:10.1016/j.ceramint.2016.06.063.

[7] B. Bernard, A. Quet, L. Bianchi, A. Joulia, A. Malié, V. Schick, B. Rémy, Thermal insulation properties of YSZ coatings: Suspension Plasma Spraying (SPS) versus Electron Beam Physical Vapor Deposition (EB-PVD) and Atmospheric Plasma Spraying (APS), Surf. Coatings Technol. $318 \quad$ (2017) 122-128. doi:10.1016/j.surfcoat.2016.06.010.

[8] E.S. P. Carpio, E. Rayón, L. Pawlowski, A. Cattini, R. Benavente, E. Bannier, M.D. Salvador, Microstructure and identaiton mechanical properties of YSZ nanostructured coatings obtained by suspension plasma spraying, Surf. Coatings Technol. 220 (2013) 237-243.

[9] N. Curry, K. VanEvery, T. Snyder, J. Susnjar, S. Bjorklund, Performance Testing of Suspension Plasma Sprayed Thermal Barrier Coatings Produced with Varied Suspension Parameters, Coatings. 5 (2015) 338-356. doi:10.3390/coatings5030338. 
[10] P. Fauchais, M. Vardelle, A. Vardelle, S. Goutier, What Do We Know, What are the Current Limitations of Suspension Plasma Spraying?, J. Therm. Spray Technol. 24 (2015) 1120-1129. doi:10.1007/s11666-015-0286-3.

[11] D. Waldbillig, O. Kesler, The effect of solids and dispersant loadings on the suspension viscosities and deposition rates of suspension plasma sprayed YSZ coatings, Surf. Coatings Technol. 203 (2009) 2098-2101. doi:10.1016/j.surfcoat.2008.11.027.

[12] F. Tarasi, M. Medraj, A. Dolatabadi, J. Oberste-Berghaus, C. Moreau, Effective parameters in axial injection suspension plasma spray process of alumina-zirconia ceramics, J. Therm. Spray Technol. 17 (2008) 685-691. doi:10.1007/s11666-008-92590 .

[13] V. Carnicer, C. Alcazar, E. Sánchez, R. Moreno, Aqueous suspension processing of multicomponent submicronic Y-TZP/Al2O3/SiC particles for suspension plasma spraying, J. Eur. Ceram. Soc. $38 \quad$ (2018) 2430-2439. doi:10.1016/j.jeurceramsoc.2018.01.006.

[14] V. Carnicer, M.J. Orts, R. Moreno, E. Sánchez, Microstructure assessment of suspension plasma spraying coatings from multicomponent submicronic Y-TZP/A12O3/SiC particles, Ceram. Int. 44 (2018) 12014-12020. doi:10.1016/j.ceramint.2018.03.186.

[15] T. Ouyang, X. Fang, Y. Zhang, D. Liu, Y. Wang, S. Feng, T. Zhou, S. Cai, J. Suo, Enhancement of high temperature oxidation resistance and spallation resistance of SiCself-healing thermal barrier coatings, Surf. Coatings Technol. 286 (2016) 365-375. doi:10.1016/j.surfcoat.2015.12.054.

[16] P. Carpio, M.D. Salvador, A. Borrell, E. Sánchez, R. Moreno, Alumina-zirconia coatings obtained by suspension plasma spraying from highly concentrated aqueous suspensions, Surf. Coatings Technol. 307 (2016) 713-719. doi:10.1016/j.surfcoat.2016.09.060.

[17] V.M. Candelario, F. Guiberteau, R. Moreno, A.L. Ortiz, Aqueous colloidal processing of submicrometric $\mathrm{SiC}$ plus $\mathrm{Y}_{3} \mathrm{Al}_{5} \mathrm{O}_{12}$ with diamond nanoparticles, J. Eur. Ceram. Soc. 33 (2013) 2473-2482. doi:10.1016/j.jeurceramsoc.2013.04.016.

[18] V.M. Candelario, M.I. Nieto, F. Guiberteau, R. Moreno, A.L. Ortiz, Aqueous colloidal processing of $\mathrm{SiC}$ with $\mathrm{Y}_{3} \mathrm{Al}_{5} \mathrm{O}_{12}$ liquid-phase sintering additives, J. Eur. Ceram. Soc. 33 (2013) 1685-1694. doi:10.1016/j.jeurceramsoc.2013.01.030.

[19] O. Burgos-Montes, R. Moreno, Stability of concentrated suspensions of Al2O3-SiO2 measured by multiple light scattering, J. Eur. Ceram. Soc. 29 (2009) 603-610. doi:10.1016/j.jeurceramsoc.2008.07.044.

[20] M. Wiśniewska, Influences of polyacrylic acid adsorption and temperature on the alumina suspension stability, 198 (2010) 258-266. doi:10.1016/j.powtec.2009.11.016. 
[21] E. Bannier, G. Darut, E. Sánchez, A. Denoirjean, M.C. Bordes, M.D. Salvador, E. Rayón, H. Ageorges, Microstructure and photocatalytic activity of suspension plasma sprayed $\mathrm{TiO}_{2}$ coatings on steel and glass substrates, Surf. Coatings Technol. 206 (2011) 378386. doi:10.1016/j.surfcoat.2011.07.039.

[22] R.A. Young, The Rietveld Method, International Union of crystallography monographs on crystallography, Oxford, Oxford, 1996.

[23] A.L. Ortiz, F. Sánchez-Bajo, N.P. Padture, F.L. Cumbrera, F. Guiberteau, Quantitative polytype-composition analyses of $\mathrm{SiC}$ using x-ray diffraction: A critical comparison between the polymorphic and the Rietveld methods, J. Eur. Ceram. Soc. 21 (2001) 12371248. doi:10.1016/S0955-2219(00)00332-0.

[24] R. Moreno Botella, Reología de suspensiones cerámicas, Consejo Superior de Investigaciones Científicas, Madrid, 2005.

[25] P. Carpio, R. Moreno, A. Gómez, M.D. Salvador, E. Sánchez, Role of suspension preparation in the spray drying process to obtain nano/submicrostructured YSZ powders for atmospheric plasma spraying, J. Eur. Ceram. Soc. 35 (2015) 237-247. doi:10.1016/j.jeurceramsoc.2014.08.008.

[26] M. Vicent, E. Sánchez, I. Santacruz, R. Moreno, Dispersion of TiO2nanopowders to obtain homogeneous nanostructured granules by spray-drying, J. Eur. Ceram. Soc. 31 (2011) 1413-1419. doi:10.1016/j.jeurceramsoc.2011.01.026.

[27] T. Molina, M. Vicent, E. Sánchez, R. Moreno, Dispersion and reaction sintering of alumina-titania mixtures, Mater. Res. Bull. 47 (2012) 2469-2474. doi:10.1016/j.materresbull.2012.05.016.

[28] P. Sokołowski, S. Kozerski, L. Pawłowski, A. Ambroziak, The key process parameters influencing formation of columnar microstructure in suspension plasma sprayed zirconia coatings, Surf. Coatings Technol. $260 \quad$ (2014) 97-106. doi:10.1016/j.surfcoat.2014.08.078.

[29] B. Bernard, L. Bianchi, A. Malié, A. Joulia, B. Rémy, Columnar suspension plasma sprayed coating microstructural control for thermal barrier coating application, J. Eur. Ceram. Soc. 36 (2016) 1081-1089. doi:10.1016/j.jeurceramsoc.2015.11.018.

[30] R. Musalek, J. Medricky, T. Tesar, J. Kotlan, Z. Pala, F. Lukac, K. Illkova, M. Hlina, T. Chraska, P. Sokolowski, N. Curry, Controlling microstructure of Yttria-stabilized zirconia prepared from suspensions and solutions by plasma spraying with High feed rates, J. Therm. Spray Technol. (2017) submitted. doi:10.1007/s11666-017-0622-x.

[31] P. Sokołowski, P. Nylen, R. Musalek, L. Łatka, S. Kozerski, D. Dietrich, T. Lampke, L. Pawłowski, The microstructural studies of suspension plasma sprayed zirconia coatings 
with the use of high-energy plasma torches, Surf. Coatings Technol. 318 (2017) 250261. doi:10.1016/j.surfcoat.2017.03.025.

[32] P. Fauchais, R. Etchart-Salas, V. Rat, J.F. Coudert, N. Caron, K. Wittmann-Ténèze, Parameters controlling liquid plasma spraying: Solutions, sols, or suspensions, J. Therm. Spray Technol. 17 (2008) 31-59. doi:10.1007/s11666-007-9152-2.

[33] P. Carpio, A. Borrell, M.D. Salvador, A. Gómez, E. Martínez, E. Sánchez, Microstructure and mechanical properties of plasma spraying coatings from YSZ feedstocks comprising nano- and submicron-sized particles, Ceram. Int. 41 (2015) 41084117. doi:10.1016/j.ceramint.2014.11.106. 